\title{
Yapay Sinir Ağları ile Çok Aşamalı Fiyat Tahmini: BIST30 Senetleri Üzerine Bir Araştırma
}

\author{
Mehmet ÖZÇALICI ${ }^{1}$
}

\begin{abstract}
$\ddot{O} z$
Zaman serileri tahmini literatürde ilgi gören bir konudur. Hisse senedi fiyatlart da zaman serisi oluşturmaktadır ve hisse senedi fiyat tahmininin birçok avantajl tarafi mevcuttur. Literatürde hisse senedi fiyat tahmini üzerine yapılan çallşmalarda genellikle bir gün sonraki fiyatların veya eğilimin tahmin edildiği görülmektedir. Bu çalı̧̧mada literatürden farkl olarak 1 gün sonraki, 2 gün sonraki ve 20 gün sonraki hisse senedi kapanıs fiyatları tahmin edilmiştir. Veri seti olarak Borsa Istanbul 30 endeksinde listelenen hisse senetlerinin Ocak 2010 ile Kasim 2015 tarihleri arasindaki fiyat ve hacim bilgileri kullanilmış ve girdi olarak teknik göstergeler hesaplanmıştır. Çalışmada tahmin yöntemi olarak yapay sinir ağları kullanilmıştır. Sonuçta hisse senetlerindeki fiyat hareketleri $\% 72.88$ e varan oranda 20 gün önceden doğru bir şekilde tahmin edilebilmiştir. Araştırmada elde edilen bulgular, orta dönemli fiyat tahminlerinin de derinlemesine inceleme gerektiren önemli bir potansiyele sahip olduğu sonucunu ortaya çıkarmaktadır.
\end{abstract}

Anahtar Kelimeler: Çok Aşamalı Fiyat Tahmini, Hisse Senedi Fiyat Tahmini, Yapay Sinir A ğları, Borsa İstanbul

JEL Sinıflandirma Kodları: C45, C53, G17

\section{Multi-Step-Ahead Stock Price Forecasting with Artificial Neural Networks: A Research on BIST30 Stocks}

\begin{abstract}
Forecasting time series is an attractive field. Stock prices are also time series and forecasting stock prices has many advantages. In previous studies, it is observed that generally one-day ahead stock prices or trends are forecasted. In this study, different from the literature, 1-day ahead, 2-days ahead and 20-days ahead closing prices are forecasted. The dataset belongs to stocks listed in Borsa Istanbul 30 Index between the period January 2010 and November 2015. Several technical indicators are used as input features. The forecasting model used in this study is artificial neural network models. At the end of the study it is observed that hit rate of 20 days ahead forecasting of stock prices reached $72.88 \%$. The results of the study reveal that multi-step ahead forecasting has important potential that deserve a deep examination.
\end{abstract}

Keywords: Multi-step-ahead price forcasting, stock price forecasting, artificial neural networks, Borsa Istanbul

JEL Classification Codes: C45, C53, G17

1 Yrd. Doç. Dr., Kilis 7 Aralık Üniversitesi, İktisadi ve İdari Bilimler Fakültesi, Uluslararası Ticaret ve Lojistik Bölümü, mozcalici@kilis.edu.tr 


\section{M. ÖZÇALICI.}

\section{GİRIŞ}

Zaman serileri tahmini literatürde uzun zamandan beri çalışılan bir konudur. Özel olarak finansal zaman serilerinin tahmin edilmesini, sürekli gelişmekte olan bir disiplin olarak tanımlamak mümkündür (Aras ve Kocakoç, 2016: 974). Zaman serisi tahmininde tek aşamalı (single-step ahead) ve çok aşamalı (multi-step ahead) tahminleri gerçekleştirmek mümkündür. Tek aşamalı zaman serisi tahmininde, girdi değişkenleri, son gözlemden hemen sonraki gözlemi tahmin etmek için kullanılmaktadır. İki ya da daha fazla zaman sonraki gözlemlerin tahmin edilmesi ise çok aşamalı tahmin olarak adlandırılmaktadır (Bao vd., 2014: 482).

Zaman serileri tahminin uygulama alanlarından biri de hisse senedi fiyat tahminidir. Hisse senedi fiyat tahmini sahip olduğu pratik ve akademik faydalar (Atsalakis vd., 2015) nedeniyle oldukça ilgi gören bir alan olarak karşımıza çıkmaktadır. Ne var ki, hisse senedi piyasaları politik, politik ve sosyal kararlardan etkilenebilmektedir. Bu nedenle hisse senedi fiyatlarının belirli bir düzeyde netlik barındırmadığını söylemek mümkündür. Bu durum hisse senedi fiyat tahminindeki başarı oranını düşürmektedir.

Eugene Fama üzerinde çok tartışılan Etkin Piyasalar Hipotezini 1970 li yıllarda literatüre sunmuştur (Fama, 1965). Etkin Piyasalar Hipotezine (EPH) göre; hisse senedi fiyatlarını önceden tahmin etmek mümkün değildir çünkü ortaya çıkan bir bilgi, anında fiyatlara yansımaktadır. Bu hipotezin geçerli olduğu ve olmadığ yönünde birçok araştırma yapılmış, kesin bir yargıya varılamamıştır. Örneğin Atan ve arkadaşları 2009 yılında yayınladıkları makalede; IMKB 'nin zayıf formda etkin olduğu sonucunu ortaya çıkarmışlardır. Bununla birlikte özellikle son zamanlarda geliştirilen yapay sinir ağları, destek vektör makineleri, ANFIS gibi bilgi işlemsel zekâ (computational intelligence) yöntemleri kullanılmak suretiyle hisse senedi fiyat tahmini gerçekleştiren çalışmalarda hisse senedi fiyatları başarı ile tahmin edilebilmektedir. Bu durum EPH ile çelişmektedir.

Literatürde yapılan çalışmalar incelendiğinde, hisse senedi fiyat tahmin çalışmalarında genellikle bir gün sonraki kapanış fiyatların tahmin edildiği 
görülmektedir. $\mathrm{Bu}$ çalışmanın literatüre katkısı, çok aşamalı fiyat tahmini gerçekleştirmektir. Çalışmada sadece bir gün sonraki fiyatlar değil, aynı zamanda 2 gün sonraki ve 20 gün sonraki hisse senedi fiyatları teknik göstergeler yardımıyla tahmin edilmiş ve sonuçlar karşılaştırılmıştır.

Çalışma 5 bölümden oluşmaktadır. Bu giriş bölümünden sonra, ikinci bölümde konu ile ilgili önceki çalışmalar yer almaktadır. Üçüncü bölümde analiz yöntemi kısaca açıklanmıştır. Dördüncü bölümde çalışmada kullanılan veri seti ve analiz sonuçları raporlanmıştır. Beşinci bölüm ise çalışmanın sonuç ve tartışma kısmını oluşturmaktadır.

\section{LITERATÜR TARAMASI}

Borsa İstanbul endekslerini veya Borsa İstanbul'da işlem gören hisse senetlerinin fiyatlarını tahmin eden ve tahmin yöntemi olarak yapay sinir ağlarını kullanan çalışmaların bazıların bazılarını şu şekilde özetlemek mümkündür. Tektaş ve Karataş (2004) çalışmalarında Borsa İstanbul'da işlem gören 7 adet hisse senedinin fiyatını yapay sinir ağları ve regresyon yöntemi ile tahmin etmeye çalışmışlardır. Çalışmalarında girdi olarak döviz kuru, enflasyon oranı ve faiz oranı gibi değişkenleri kullanmışlardır. Haftalık ve günlük iki adet tahmin gerçekleştirmişlerdir. Tahmin performansını korelasyon katsayısı ile ölçmüşlerdir. Çalışma sonunda yapay sinir ağlarının başarılı bir şekilde hisse senetlerini doğru tahmin edebildiğini raporlamaktadırlar. Toraman (2008) çalışmasında demir-çelik sektöründe faaliyet gösteren hisse senetlerinin fiyatlarını yapay sinir ağları ile tahmin etmiştir. Çalışmasında finansal oranları girdi olarak kullanmıştır ve performans ölçütü olarak istatistiksel tahmin performans ölçülerini kullanmıştır. Sonuçta yapay sinir ağlarının fiyat tahminini başarılı bir şekilde gerçekleştiği raporlanmaktadır. Avcı (2009) çalışmasında hisse senedi getirilerini yapay sinir ağları ile tahmin etmiştir. BIST30 endeksine kayıtlı 5 adet bankanın hisse senetlerinin beş aylık getirileri tahmin edilmiştir. Çalışma sonunda yazar, yapay sinir ağları modellerinin al ve tut stratejisinden daha yüksek getiri ağladığını raporlamaktadır. Kara ve arkadaşları (2011) çalışmalarında BIST100 endeksini tahmin etmeye çalışmışlardır. Girdi değişkenleri olarak teknik göstergeler 


\section{M. ÖZÇALICI.}

kullanmışlar ve gerek yapay sinir ağlarının gerekse de destek vektör makinelerinin parametrelerini veri setinin bir kısmını kullanmak suretiyle belirlemişlerdir. Çalışmalarının sonunda yapay sinir ağlarının destek vektör makinelerinden daha iyi sonuç verdiğini raporlamışlardır. Yakut ve arkadaşları (2014) çalışmalarında yapay sinir ağları ve destek vektör makineleri yöntemleriyle borsa endeksi tahmini gerçekleştirmişlerdir. Çalışmalarında BIST endeksini tahmin etmişler ve girdi olarak döviz kurları, diğer ülkelerin borsaları gibi değişkenleri kullanmışlardır. Sonuçta yapay sinir ağları ve destek vektör makineleri yöntemlerinin borsa indeks tahmininde başarılı bir şekilde kullanılabileceğini raporlamaktadırlar. Çalışkan ve Deniz (2015) çalışmalarında BIST30 endeksinde yer alan senetlerin fiyatlarını tahmin etmişlerdir. Çalışmalarında girdi değişkenleri olarak döviz kurları, altın fiyatları, hisse senetlerinin kapanış fiyatları gibi değişkenleri kullanmışlardır. Çalışma sonunda, yapay sinir ağları modelinin hisse senedi fiyat tahmininde başarılı bir şekilde kullanılabileceğini raporlamaktadırlar. Özçalıcı (2015) doktora tezinde BIST30 endeksinde işlem gören hisse senetlerinin kapanış fiyatlarını tahmin edecek melez bir yöntem geliştirmiştir. Söz konusu tezde, tahmin yöntemi olarak yapay sinir ağlarını kullanmıştır ve ara katmanda yer alması gereken nöron sayısının belirlenmesinde ve değişken seçiminde genetik algoritmalar kullanılmıştır. Çalışma sonunda önerilen melez yöntemin hisse senedi fiyat tahmini başarısını geliştirdiğini raporlamaktadır.

Çok aşamalı tahmin yapan çalışmaları ise şu şekilde özetlemek mümkündür. Huck (2010) SP100 indeksinde listelenen hisse senetleri için kısa ve uzun dönemli tahmin gerçekleştirmiştir. Yapay sinir ağları ve çok kriterli karar verme tekniklerinden oluşan melez bir yöntem önermişlerdir. Dört hafta (20 gün) öncesine kadar tahmin işlemini gerçekleştirmişlerdir. Xiong ve arkadaşları (2013) ham petrol fiyatlarını 24 haftaya varan periyodda önceden tahmin etmek için bir model geliştirmişlerdir. Ali ve Pınar (2016) Türkiye'de faaliyet gösteren bir perakende zinciri için, birden fazla zaman dilimini kapsayan bir tahmin çalışması gerçekleştirmiştir. Çalışmalarında 12 ay kadar önceden satış tahmini gerçekleştirmişlerdir. Tahmin performansı MAPE ve MAE gibi istatistiksel 
yöntemlerle ölçülmüştür. Tahmin etmek için geliştirdikleri yeni yöntemi çalışmalarında anlatmaktadırlar. Önerdikleri modelin uzun dönemli tahminde daha başarılı olduklarını raporlamaktadırlar.

Litreratürde yer alan ve yukarıda incelenen çalışmalarda, Borsa İstanbul 'da işlem gören hisse senetleri için uzun dönemli fiyat tahminin gerçekleştirilmediği görülmektedir. Bu çalışmada bu açığı gidermek amacıyla, Borsa İstanbul'da işlem gören hisse senetlerinin kapanış fiyatlarının çok aşamalı tahmin edilebilirliği araştırılmıştır.

\section{METODOLOJI}

Bu bölümde çalışmada kullanılan temel analiz yöntemi olan çok katmanlı yapay sinir ağları kısaca tanıtılacaktır.

\section{1. Çok Katmanlı Yapay Sinir Ağları}

Yapay sinir ağları üzerine yapılan çalışmalar insan zihninin bilgi işleme yönteminden ilham almaktadır (Haykin, 1999: 23)

Yapay Sinir ağları literatüre tanıtıldığından beri birçok farklı çeşitteki yapay sinir ağları modelleri geliştirilmiştir. Fakat çok katmanlı yapay sinir ağları modeli bu modeller içinde en yaygın kullanılan modeldir ve zaman serilerinin tahmini için idealdir (Palit ve Popovic, 2005: 80). Çok katmanlı yapay sinir ağları genellikle girdi katmanı, ara katman ve çıktı katmanı olmak üzere üç katmandan oluşmaktadır (Şekil 1). Söz konusu katmanlarda nöronlar yer almaktadır ve bu nöronlar birbirleriyle bağlantılıdır. Kısmi bağlantılar içeren modeller de mevcuttur ancak bu çalışmada kullanılan tahmin modelinde her nöronun birbirleriyle bağlantısı vardır. 


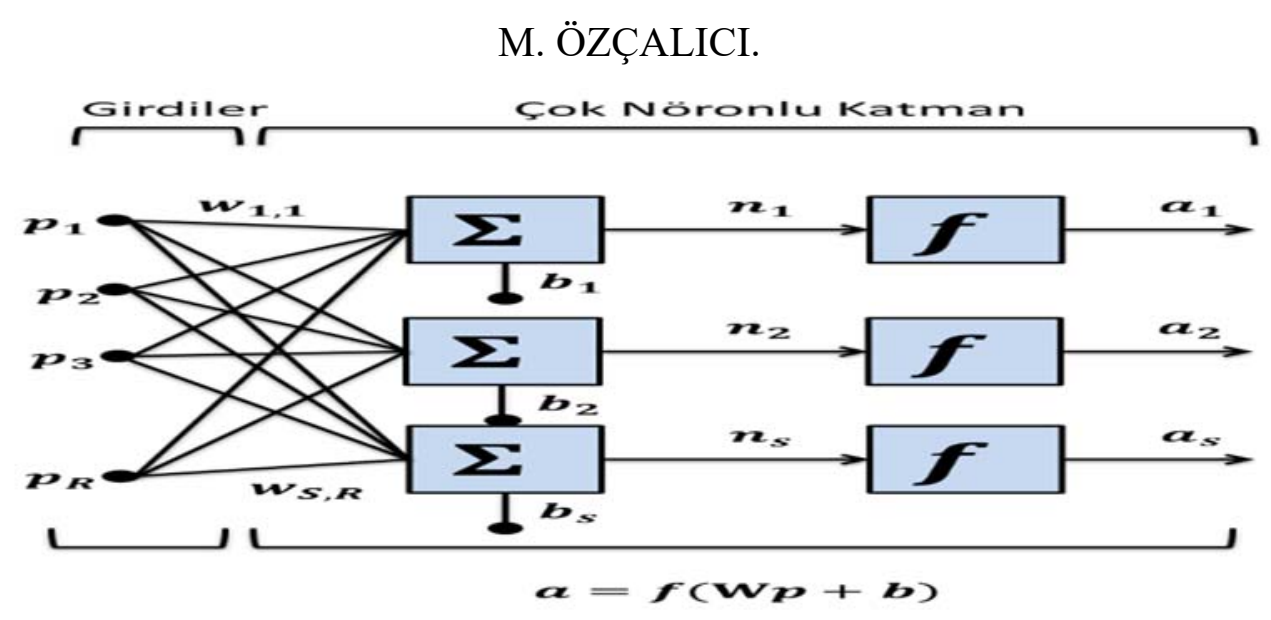

Şekil 1. Çok Katmanlı Yapay Sinir Ağları Modeli

Kaynak: Hagan, vd. 1996: 2-9.

Çalışmada yapay sinir ağlarının eğitilmesi için Levenberg-Marquardt eğitim algoritması kullanılmıştır. LM algoritması yenilemeler ile çalışmaktadır ve her bir adımda ağırlık değerleri ile eşik değerleri değiştirilmektedir. Ağırlıklar öğrenme parametresi $(\mu)$ adı verilen bir parametre ile kontrol edilmektedir. Öğrenme parametresi olan $\mu$ değeri eğitim süreci boyunca artmakta veya azalmaktadır (Asadi vd., 2012). Söz konusu $\mu$ değeri büyük değerler aldığında LM algoritması speepest descent algoritması gibi davranmaktadır. Bununla beraber $\mu$ değeri küçük değerler aldığında ise LM algoritması Gauss-Newton algoritması gibi davranmaktadır. Bu eğitim sürecinden sonra yapay sinir ağları modelindeki ağırlık ve eşik değerleri belirlenmiş olmaktadır.

Tek bir katmanı olan yapay sinir ağları modelinin herhangi bir sürekli fonksiyonu modelleyebileceği kanıtlanmıştır (Hornik ve Stinchcombe, 1989). Sahip olduğu bu avantaj ile birlikte, yapay sinir ağları, hisse senedi fiyat tahmini yanı sıra farklı finansal alanlarda da başarıyla kullanılmaktadır. Bankaların finansal başarısızlığının tahmin edilmesinde (Altunöz, 2013), bankacılık sektöründe finansal güç derecelerinin tahmin edilmesi (Boyacıoğlu ve Kara, 2007), enflasyon tahmini (Uslu vd., 2012) ve banka müşterilerinin bölümlendirilmesi (Özçalıcı, 2011) örneklerinde olduğu gibi. 


\section{ANALIZ}

$\mathrm{Bu}$ bölümde sırasıyla çalışmada kullanılan veri setinin içeriğine, çalışmada kullanılan yöntemin parametrelerine ve analiz sonuçlarına yer verilecektir.

\subsection{Veri Seti}

Çalışmada, 2015 yılının son çeyreğinde Borsa Istanbul 30 Endeksinde listelenen 30 adet hisse senedinin tamamı kullanılmıştır. BIST30 Ulusal Endeksinde yer alan hisse senetlerinin kullanılmasının nedeni, bu endekste yer alan senetlerin yüksek işlem hacmine sahip olmasıdır. 30 adet hisse senedi için Ocak 2010 tarihi ile Kasım 2015 tarihleri arasındaki tarihi açllış, kapanış, en yüksek, en düşük fiyat ve işlem hacmi bilgileri Borsa İstanbul Datastore departmanından temin edilmiştir. Bu tarih aralığı, çalışmanın yapıldığı tarihte erişilebilecek en güncel veri setini içermektedir. Çalışmada en güncel 60 adet fiyat test amacıyla kullanılırken geri kalan 2700 adet seans eğitim amacıyla kullanılmıştır.

Hisse senedi tahmin çalışmalarında temel veya teknik göstergeler kullanılmaktadır. Temel göstergelere ihracat, ithalat, para arzı, faiz oranı, enflasyon oranı, döviz kurları, işsizlik rakamları ve firmalara ait finansal tablolardan hesaplanan finansal oranlar örnek olarak verilebilir (Atsalakis ve Valavanis, 2009a: 10697). Teknik analiz ise fiyat hareketlerinin birbirlerini takip edeceği görüşüne dayanmaktadır (Edwards ve Magee, 2007). Teknik analizde, geçmiş fiyat ve işlem hacmi bilgilerinden yola çıkmak suretiyle teknik göstergeler hesaplanmaktadır. Çok fazla sayıda teknik gösterge hesaplamak mümkündür. Teknik göstergelerden bazılarına ilişkin formüller ve açıklamalar (Achelis, 2000) çalışmasında yer almaktadır. Eğer tahmin periyodu bir yıl veya daha fazlasını kapsayacaksa temel göstergeler, eğer tahmin periyodu bir yıldan daha az bir süreyi kapsıyorsa, teknik göstergelerin kullanılması gerekmektedir (Atsalakis ve Valavanis, 2009a:10697). $\mathrm{Bu}$ çalışmada kısa ve orta düzeyli tahmin gerçekleştirildiğinden dolayı teknik göstergeler kullanılmıştır. Çalışmada, girdi seti oluşturulurken ilk olarak literatürde yer alan ve sıklıkla kullanılan teknik göstergeler bir araya getirilmiştir (Diler, 2003; Kara vd., 2011; Chang vd., 2012). Birbirleriyle yüksek korelasyona sahip olan 


\section{M. ÖZÇALICI.}

değişkenlerin bir arada kullanılması çoklu eşdoğrusallık (multicollinearity) problemini ortaya çıkaracaktır. $\mathrm{Bu}$ nedenle, eğitim veri setinde değişkenlerin korelasyon katsayısı hesaplanmış ve birbirleriyle düşük korelasyon katsayısına sahip olan üç adet değişken girdi olarak seçilmiştir. Çalışmanın ekinde her bir hisse senedi için girdi değişkenleri arasındaki Pearson Korelasyon katsayısı tablo halinde sunulmuştur. $\mathrm{Bu}$ değişkenler ve formülleri Tablo 1 'deki gibidir. Hareketli ortalamalar en eski ve en popüler teknik göstergelerden biridir (Achelis, 2000). Stokastik göstergeler bir hisse senedinin kapanış fiyatını, belirli bir dönemdeki fiyat aralığı ile karşılaştırmaktadır (Edwards ve Magee, 2007: 654). Temel gösterge $\% \mathrm{~K}$ göstergesidir. $\mathrm{Bu}$ değerin hareketli ortalamasını hesaplamak suretiyle \%D göstergesine ulaşılmaktadır. MACD göstergesi ise haraketli ortalamalar arasındaki ilişkiyi göstermektedir (Achelis, 2000).

Tablo 1. Çalışmada Kullanılan Girdi Değişkenleri

\begin{tabular}{|l|l|}
\hline Değişkenin ismi & Denklemi \\
\hline 10 günlük hareketli ortalama & $S M A(10)=\frac{1}{10} \sum_{i=1}^{10} K_{t-i}$ \\
\hline$\% \mathrm{D}$ & $\begin{array}{c}\%=\frac{K_{t}-L L_{t-10}}{H H_{t-10}-L L_{t-10}} \times 100 \\
\% \mathrm{D}=\text { Stokastik } \% \mathrm{~K} \text { nin } 3 \text { günlük hareketli } \\
\text { ortalamas1 }\end{array}$ \\
\hline MACD & $\frac{8}{10} M A C D_{t-1}+\frac{2}{10} \times D I F F_{i}$ \\
\hline
\end{tabular}

$K_{t}$ kapanış fiyatı, $H H_{t}$ son $t$ günde en yüksek yüksek fiyat, $L L_{t}$ son $t$ günde en düşük düşük fiyat, $D I F F_{i}=E M A_{12}-E M A_{26}$

\section{2. Çalışma Parametreleri}

Yapay sinir ağlarının eğitiminde, hisse senedi fiyat tahmin çalışmalarında sıklıkla kullanılan (Atsalakis ve Valavanis, 2009a) Levenberg-Marquardt (LM) eğitim algoritması kullanılmıştır. Yapay sinir ağlarının en önemli dezavantajlarından biri kullanıcının birçok parametreye karar vermesi zorunluluğudur. Çalışmada kullanılan yapay sinir ağlarına ilişkin bazı parametreler şu şekildedir: Epoch sayısı 1000, başlangıç $\mu$ 0.001, $\mu$ artış faktörü $0.1, \mu$ azalış faktörü 10, en yüksek $\mu$ ise 1e10. Yapay sinir ağları eğitilirken eğitim seti, kendi 
içinde eğitim (\%70), doğrulama (\%15) ve test $(\% 15)$ olmak üzere üç gruba ayrılmıştır.

Yapay sinir ağları analizi kullanılırken kullanıcının karar vermesi gereken parametrelerden bir diğeri de ara katmanda yer alması gereken nöron sayısıdır. Her problemin zorluk derecesine göre ara katmanda yer alması gereken nöron sayısı da değişecektir. Ara katmanda yer alması gereken nöron sayısının belirlenmesinde hazır bir yöntem söz konusu değildir. Bu nedenle bu çalışmada ara katmanda 3, 7 ve 10 adet nöronun kullanıldığ yapay sinir ağları modelleri oluşturulmuş ve tahmin sonuçları incelenmiştir.

\subsection{Tahmin Sonuçları}

Çalışmada yön tahmini doğru tahmin oranı adı verilen bir performans ölçüsü ile hesaplanmıştır. Söz konusu performans ölçüsü literatürde hisse senedi fiyat tahmini çalışmalarını değerlendirmek için kullanılmaktadır (Kara vd., 2011; Diler, 2003; Altay ve Satman, 2005). Hisse senedi tahmin performansını MAPE, RMSE, MAE gibi istatistiksel performans ölçüleri ile de ölçmek mümkündür. Fakat farklı çalışmalarda kullanılan zaman periyodunun ve kullanılan normalizasyon tekniklerinin farklı olması gibi nedenlerden ötürü istatistiksel performans ölçüleri farklı sonuçlar ortaya çıkarmaktadır ve sağlıklı karşıllaştırmaya imkân vermemektedir. Farklı çalışmalarda elde edilen sonuçların performansı doğru tahmin oranı ile karşılaştırılabilir (Atsalakis ve Valavanis, 2009b). Doğru tahmin oranını hesaplamak için, çalışmada tahmin edilen fiyatlar aşağıdaki formül yardımıyla eğilim serisine çevrilmektedir.

$$
e= \begin{cases}1, & f_{t+1} \geq f_{t} \\ 0, & f_{t+1}<f_{t}\end{cases}
$$

formülde, $e$ eğilim serisini, $f_{t+1}$ ifadesi $t+1$ günündeki fiyatı ve $f_{t}$ ise $t$ günündeki fiyatı temsil etmektedir. $e$ eğilim serisi hem tahmin edilen fiyatlar, hem de gerçek fiyatlar için hesaplanabilir. Tahmin edilen serinin performansı aşağıdaki formül yardımıyla hesaplanabilir. 


\section{M. ÖZÇALICI.}

$$
\text { DTO }=\frac{p+n}{t}
$$

formülde, $p$ bir sonraki gün fiyat artışının doğru bir şekilde tahmin edildiği seans sayısını, $n$ bir sonraki gün fiyat azalışının doğru bir şekilde tahmin edildiği seans sayısinı ve $t$ ise test periodunu temsil etmektedir.

Tablo 2 'de, 30 adet hisse senedi için ara katmanda sırasıyla 3, 7 ve 10 adet nöronun yer aldığı yapay sinir ağları modellerinin ürettiği bir gün sonraki fiyat ve iki gün sonraki fiyat tahminlerinden hesaplanan doğru tahmin oranları yer almaktadır. Tabloda aynı zamanda iki gün sonraki doğru tahmin oranının bir gün sonraki doğru tahmin oranından büyük olduğu senet bilgileri de yer almaktadır. Tablodaki sonuçlar göz önüne alındığında 3,7 ve 10 nörona sahip yapay sinir ağları modellerinde sırasıyla 9, 12 ve 11 adet hisse senetlerinde iki gün sonraki fiyatların, bir gün sonraki fiyatlardan daha başarılı bir şekilde doğru tahmin edildiği görülmektedir. Bir sonraki gün için doğru tahmin oranının en yüksek gerçekleştiği senet EKGYO kodlu senettir ve ara katmanda 10 adet nöronun kullanıldığ 1 yapay sinir ağları modelinde fiyat hareketlerinin $\% 66.1$ oranında bir gün bir gün öncesinden doğru tahmin edilebildiği görülmüştür. İki gün sonraki fiyatın tahmin edildiği modellerde ise en yüksek doğru tahmin oranı ARCLK kodlu senede aittir ve ara katmanda 10 adet nöronun kullanıldığı yapay sinir ağları modelinde fiyat hareketlerinin \%66.1 oranında iki gün öncesinden doğru olarak tahmin edilebildiği görülmüştür.

Tablo 2. Bir Gün Sonraki Fiyat Tahmini ve 2 Gün Sonraki Fiyat Tahmin Sonuçları

\begin{tabular}{|l|l|l|l|l|l|l|l|l|l|l|}
\hline & \multicolumn{3}{|l|}{1 gün sonraki tahmin (\%) } & \multicolumn{2}{l|}{$\begin{array}{l}\text { gün sonraki tahmin } \\
(\%)\end{array}$} & \multicolumn{2}{l|}{$2>1 *$} \\
\hline Nöron Say1s1 & 3 & 7 & 10 & 3 & 7 & 10 & 3 & 7 & 10 \\
\hline AKBNK & 40.68 & 42.37 & 42.37 & 42.37 & 44.07 & 44.07 & 1 & 1 & 1 \\
\hline ARCLK & 49.15 & 49.15 & 42.37 & 57.63 & 59.32 & 66.1 & 1 & 1 & 1 \\
\hline BIMAS & 55.93 & 50.85 & 52.54 & 61.02 & 61.02 & 61.02 & 1 & 1 & 1 \\
\hline
\end{tabular}


Dokuz Eylül Üniversitesi İktisadi ve İdari Bilimler Fakültesi Dergisi Cilt:31, Sayl:2, Yll:2016, ss. 209-227

\begin{tabular}{|l|l|l|l|l|l|l|l|l|l|}
\hline CCOLA & 50.85 & 50.85 & 50.85 & 57.63 & 54.24 & 61.02 & 1 & 1 & 1 \\
\hline DOAS & 62.71 & 57.63 & 59.32 & 61.02 & 54.24 & 59.32 & 0 & 0 & 0 \\
\hline EKGYO & 57.63 & 54.24 & 66.1 & 57.63 & 50.85 & 47.46 & 0 & 0 & 0 \\
\hline ENKAI & 38.98 & 40.68 & 40.68 & 40.68 & 40.68 & 42.37 & 1 & 0 & 1 \\
\hline EREGL & 59.32 & 59.32 & 59.32 & 49.15 & 44.07 & 47.46 & 0 & 0 & 0 \\
\hline FROTO & 50.85 & 49.15 & 52.54 & 42.37 & 44.07 & 38.98 & 0 & 0 & 0 \\
\hline GARAN & 52.54 & 52.54 & 50.85 & 35.59 & 40.68 & 37.29 & 0 & 0 & 0 \\
\hline HALKB & 49.15 & 44.07 & 47.46 & 42.37 & 44.07 & 45.76 & 0 & 0 & 0 \\
\hline ISCTR & 50.85 & 52.54 & 50.85 & 42.37 & 40.68 & 40.68 & 0 & 0 & 0 \\
\hline KCHOL & 52.54 & 57.63 & 50.85 & 57.63 & 61.02 & 55.93 & 1 & 1 & 1 \\
\hline KOZAL & 44.07 & 44.07 & 44.07 & 40.68 & 44.07 & 38.98 & 0 & 0 & 0 \\
\hline KRDMD & 52.54 & 50.85 & 52.54 & 54.24 & 50.85 & 52.54 & 1 & 0 & 0 \\
\hline OTKAR & 50.85 & 50.85 & 52.54 & 42.37 & 42.37 & 44.07 & 0 & 0 & 0 \\
\hline PETKM & 54.24 & 54.24 & 47.46 & 50.85 & 52.54 & 42.37 & 0 & 0 & 0 \\
\hline PGSUS & 52.54 & 44.07 & 54.24 & 37.29 & 61.02 & 57.63 & 0 & 1 & 1 \\
\hline SAHOL & 59.32 & 54.24 & 57.63 & 57.63 & 54.24 & 55.93 & 0 & 0 & 0 \\
\hline SISE & 64.41 & 62.71 & 61.02 & 55.93 & 57.63 & 55.93 & 0 & 0 & 0 \\
\hline TAVHL & 54.24 & 54.24 & 44.07 & 54.24 & 47.46 & 42.37 & 0 & 0 & 0 \\
\hline TCELL & 64.41 & 59.32 & 64.41 & 61.02 & 61.02 & 62.71 & 0 & 1 & 0 \\
\hline THYAO & 50.85 & 47.46 & 49.15 & 50.85 & 49.15 & 55.93 & 0 & 1 & 1 \\
\hline TKFEN & 55.93 & 59.32 & 55.93 & 47.46 & 54.24 & 45.76 & 0 & 0 & 0 \\
\hline TOASO & 50.85 & 40.68 & 50.85 & 47.46 & 45.76 & 52.54 & 0 & 1 & 1 \\
\hline TTKOM & 50.85 & 49.15 & 47.46 & 54.24 & 42.37 & 50.85 & 1 & 0 & 1 \\
\hline TUPRS & 52.54 & 52.54 & 50.85 & 55.93 & 57.63 & 54.24 & 1 & 1 & 1 \\
\hline ULKER & 52.54 & 55.93 & 54.24 & 49.15 & 57.63 & 49.15 & 0 & 1 & 0 \\
\hline VAKBN & 50.85 & 47.46 & 47.46 & 45.76 & 49.15 & 45.76 & 0 & 1 & 0 \\
\hline YKBNK & 49.15 & 50.85 & 52.54 & 42.37 & 47.46 & 47.46 & 0 & 0 & 0 \\
\hline Toplam & & & & & & & 9 & 12 & 11 \\
\hline *2 gün sonraki doğru tahmin oran1 > 1 gün sonraki doğru tahmin oran1 & & \\
\hline
\end{tabular}

Tablo 3 'de ise 30 adet hisse senedi için ara katmanda sırasıyla 3, 7 ve 10 adet nöronun yer aldığı yapay sinir ağları modellerinin ürettiği 1 gün sonraki fiyat ve 20 gün sonraki fiyat tahminlerinden hesaplanan doğru tahmin oranları yer almaktadır. 


\section{M. ÖZÇALICI.}

Tabloda aynı zamanda 20 gün sonraki doğru tahmin oranının 1 gün sonraki doğru tahmin oranından büyük olduğu senet bilgileri de yer almaktadır. Tablodaki sonuçlar göz önüne alındığında 3, 7 ve 10 adet nörona sahip yapay sinir ağları modellerinde, sirasiyla 16,13 ve 17 adet hisse senetlerinde 20 gün sonraki fiyatların, 1 gün sonraki fiyatlardan daha başarılı bir şekilde doğru tahmin edildiği görülmektedir. 20 gün sonraki fiyatın tahmin edildiği modellerde en yüksek doğru tahmin oranı TOASO kodlu hisse senedine aittir ve ara katmanda 10 adet nöronun kullanıldı ̆̆ yapay sinir ağları modelinde fiyat hareketlerinin, \%72.88 oranında 20 gün öncesinden doğru olarak tahmin edilebildiği belirlenmiştir.

Tablo 3. Bir Gün Sonraki Fiyat Tahmini ve 20 Gün Sonraki Fiyat Tahmin Sonuçları

\begin{tabular}{|l|l|l|l|l|l|l|l|l|l|}
\hline & \multicolumn{2}{|l}{1 gün sonraki tahmin (\%) } & \multicolumn{2}{l|}{20 gün sonraki tahmin (\%) } & \multicolumn{3}{|l|}{$20>1 *$} \\
\hline $\begin{array}{l}\text { Nöron } \\
\text { Say1S1 }\end{array}$ & 3 & 7 & 10 & 3 & 7 & 10 & 3 & 7 & 10 \\
\hline AKBNK & 40.68 & 42.37 & 42.37 & 52.54 & 45.76 & 52.54 & 1 & 1 & 1 \\
\hline ARCLK & 49.15 & 49.15 & 42.37 & 57.63 & 52.54 & 57.63 & 1 & 1 & 1 \\
\hline BIMAS & 55.93 & 50.85 & 52.54 & 61.02 & 49.15 & 55.93 & 1 & 0 & 1 \\
\hline CCOLA & 50.85 & 50.85 & 50.85 & 62.71 & 61.02 & 55.93 & 1 & 1 & 1 \\
\hline DOAS & 62.71 & 57.63 & 59.32 & 38.98 & 42.37 & 42.37 & 0 & 0 & 0 \\
\hline EKGYO & 57.63 & 54.24 & 66.1 & 49.15 & 50.85 & 45.76 & 0 & 0 & 0 \\
\hline ENKAI & 38.98 & 40.68 & 40.68 & 52.54 & 49.15 & 45.76 & 1 & 1 & 1 \\
\hline EREGL & 59.32 & 59.32 & 59.32 & 45.76 & 38.98 & 44.07 & 0 & 0 & 0 \\
\hline FROTO & 50.85 & 49.15 & 52.54 & 52.54 & 37.29 & 37.29 & 1 & 0 & 0 \\
\hline GARAN & 52.54 & 52.54 & 50.85 & 55.93 & 50.85 & 55.93 & 1 & 0 & 1 \\
\hline HALKB & 49.15 & 44.07 & 47.46 & 52.54 & 59.32 & 50.85 & 1 & 1 & 1 \\
\hline ISCTR & 50.85 & 52.54 & 50.85 & 52.54 & 54.24 & 54.24 & 1 & 1 & 1 \\
\hline KCHOL & 52.54 & 57.63 & 50.85 & 57.63 & 54.24 & 57.63 & 1 & 0 & 1 \\
\hline KOZAL & 44.07 & 44.07 & 44.07 & 55.93 & 52.54 & 50.85 & 1 & 1 & 1 \\
\hline KRDMD & 52.54 & 50.85 & 52.54 & 52.54 & 54.24 & 54.24 & 0 & 1 & 1 \\
\hline OTKAR & 50.85 & 50.85 & 52.54 & 57.63 & 59.32 & 47.46 & 1 & 1 & 0 \\
\hline PETKM & 54.24 & 54.24 & 47.46 & 49.15 & 52.54 & 54.24 & 0 & 0 & 1 \\
\hline PGSUS & 52.54 & 44.07 & 54.24 & 59.32 & 61.02 & 62.71 & 1 & 1 & 1 \\
\hline SAHOL & 59.32 & 54.24 & 57.63 & 59.32 & 49.15 & 59.32 & 0 & 0 & 1 \\
\hline
\end{tabular}


Dokuz Eylül Üniversitesi İktisadi ve İdari Bilimler Fakültesi Dergisi Cilt:31, Sayl:2, Yll:2016, ss. 209-227

\begin{tabular}{|c|c|c|c|c|c|c|c|c|c|}
\hline SISE & 64.41 & 62.71 & 61.02 & 64.41 & 55.93 & 59.32 & 0 & 0 & 0 \\
\hline TAVHL & 54.24 & 54.24 & 44.07 & 50.85 & 47.46 & 44.07 & 0 & 0 & 0 \\
\hline TCELL & 64.41 & 59.32 & 64.41 & 66.1 & 55.93 & 59.32 & 1 & 0 & 0 \\
\hline THYAO & 50.85 & 47.46 & 49.15 & 55.93 & 57.63 & 57.63 & 1 & 1 & 1 \\
\hline TKFEN & 55.93 & 59.32 & 55.93 & 38.98 & 55.93 & 37.29 & 0 & 0 & 0 \\
\hline TOASO & 50.85 & 40.68 & 50.85 & 42.37 & 54.24 & 72.88 & 0 & 1 & 1 \\
\hline TTKOM & 50.85 & 49.15 & 47.46 & 52.54 & 47.46 & 50.85 & 1 & 0 & 1 \\
\hline TUPRS & 52.54 & 52.54 & 50.85 & 42.37 & 40.68 & 44.07 & 0 & 0 & 0 \\
\hline ULKER & 52.54 & 55.93 & 54.24 & 49.15 & 55.93 & 44.07 & 0 & 0 & 0 \\
\hline VAKBN & 50.85 & 47.46 & 47.46 & 45.76 & 54.24 & 47.46 & 0 & 1 & 0 \\
\hline YKBNK & 49.15 & 50.85 & 52.54 & 45.76 & 45.76 & 47.46 & 0 & 0 & 0 \\
\hline \multicolumn{7}{|l|}{ Toplam } & 16 & 13 & 17 \\
\hline
\end{tabular}

Çalışmada elde edilen sonuçları görselleştirebilmek için tahmin sonuçları, zaman grafiği halinde görselleştirilmiştir. Şekil 2 'de TOASO isimli hisse senedinin kapanış fiyatları zaman grafiği halinde gösterilmiştir. Şekilde aynı zamanda doğru tahmin edilen yönler "o" harfi ile işaretlenmiştir. Başka bir ifade ile her "o" işaretinden sonraki fiyat hareketi, 20 gün önceden doğru bir şekilde tahmin edilebilmiştir.

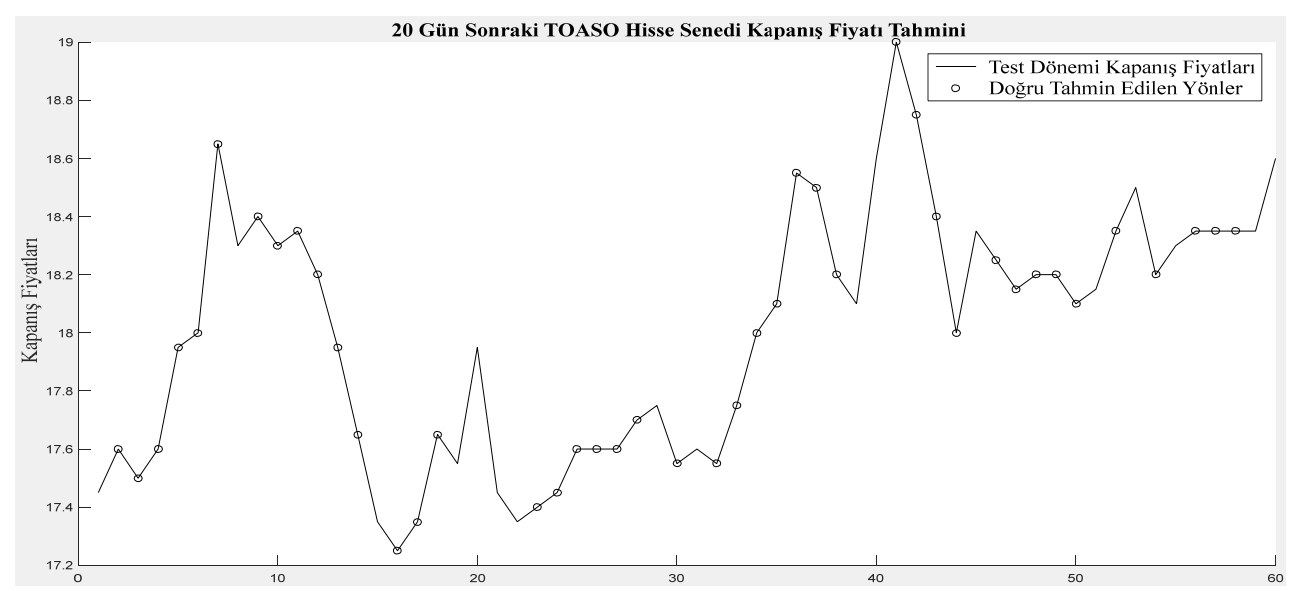

Şekil 2. TOASO Hisse Senedinin Kapanış Fiyatı ve 20 Gün Önceden Doğru Tahmin Edilen Eğilim 


\section{M. ÖZÇALICI.}

Tablo 4'de literatürde gerek Borsa İstanbul'da faaliyet gösteren gerekse de BIST endekslerini kullanan benzer çalışmaların doğru tahmin oran sonuçları yer almaktadır. Bu çalışmada yirmi gün sonraki fiyat hareketi literatürde yer alan çalışmaların birçoğundan yüksek çıkmıştır. $\mathrm{Bu}$ durum orta dönemli fiyat hareketlerinin yüksek doğrulukla tahmin edileceğini ortaya çıkarmaktadır.

Tablo 4. Önceki Çalışma Sonuçları ile Karşılaştırılması

\begin{tabular}{|l|c|}
\hline Çalı̧̧ma & Doğru Tahmin Oranı \\
\hline Kara vd (2011) & $\% 75.74$ \\
\hline Bu çalışma (20 gün sonraki doğru tahmin oranı) & $\% 72.88$ \\
\hline Diler (2003) & $\% 60.81$ \\
\hline Özçalıcı (2015) & $\% 60.00$ \\
\hline Çalışkan ve Deniz (2015) & $\% 58.00$ \\
\hline Altay ve Satman (2005) & $\% 57.80$ \\
\hline
\end{tabular}

\section{SONUÇ VE TARTIŞMA}

Kişilerin ve firmaların fazla fonlarını değerlendirdikleri hisse senetleri piyasasında, hisse senetlerinin fiyatlarının doğru bir şekilde tahmin edilebilmesi her türlü finansal karar verici için önemli bir konudur. Özellikle gelişmekte olan ülkelerde, borsada doğru kararların alınması ekonominin genel yapısını da etkileyecektir. $\mathrm{Bu}$ ve benzeri nedenlerle literatürde son zamanlarda, hisse senetleri fiyatlarının veya fiyatlarındaki yönlerin doğru bir şekilde tahmin edilmesini sağlayacak yöntemler geliştirilmektedir.

Literatürde yapılan çalışmalar incelendiğinde, genellikle hisse senedinin bir sonraki gündeki fiyatının veya fiyat eğiliminin tahmin edilmeye çalışıldığ 1 görülmektedir. Bu çalışmada ise 1 gün sonraki, 2 gün sonraki ve 20 gün sonraki fiyatlar tahmin edilmiş ve hangi durumda en yüksek tahmin performansının gerçekleştiği incelenmiştir. Çalışmada, Borsa İstanbul 30 endeksinde yer alan hisse senetleri ve ara katmanında 3, 7 ve 10 adet nöronun yer aldığı yapay sinir ağları modelleri kullanılmıştır. Çalışmada 2 gün sonraki fiyat tahmin oranları ile 1 gün sonraki fiyat tahmin oranları karşılaştırılmıştır. Aynı şekilde 20 gün sonraki fiyat 
tahmin oranları ve 1 gün sonraki fiyat tahmin oranları karşılaştırılmıştır. Sonuçta, daha fazla hisse senedinde 20 gün sonra fiyattaki eğilimin, 1 gün sonraki fiyat eğiliminden daha doğru oranda tahmin edilebildiği ortaya çıkmıştır. Çalışmada TOASO adlı hisse senedinin fiyatı 20 gün öncesinden $\% 72.88$ oranında doğru bir şekilde tahmin edilebilmiştir ve ulaşılan bu değer literatürde yapılan çalışmaların çoğundan yüksektir. Böylelikle orta dönemli fiyat tahminlerinin de derinlemesine inceleme gerektiren önemli bir potansiyele sahip olduğu sonucu ortaya çıkmaktadır.

Çalışmada elde edilen sonuçlar başarılı olsa da çalışmanın bazı kısıtları söz konusudur. İlk olarak parametrelerin oluşturulmasında herhangi bir optimizasyon yöntemi kullanılmamıştır. Aynı şekilde değişkenlerin seçiminde de özellik seçim algoritması kullanılmamıştır. Bununla birlikte 1, 2 ve 20 gün sonraki fiyat tahminleri gerçekleştirilmiştir. Gelecek çalışmalarda optimizasyon yöntemleri ile birlikte daha yüksek doğrulukta hisse senedi fiyat tahmini gerçekleştirebilmek mümkün olabilecektir. Kısa ve orta dönem daha geniş ölçekte değerlendirilebilir.

\section{KAYNAKÇA}

ACHELIS, S. (2000), Technical Analysis from A to Z, (2. Bask1), McGraw Hill, New York,

ALİ, Ö.G., PINAR, E. (2016), "Multi-Period-Ahead Forecasting with Residual Extrapolation and Information Sharing - Utilizing A Multitude of Retail Series", International Journal of Forecasting, 32, 502-517.

ALTAY, E., SATMAN, M.H. (2005), "Stock market forecasting: Artificial neural network and linear regression comparison in an emerging market", Journal of Financial Management and Analysis, 18(2), 18-33.

ALTUNÖZ, U. (2013), "Bankaların Finansal Başarısızlıklarının Yapay Sinir Ağları Modeli Çerçevesinde Tahmin Edilebilirliği”, Dokuz Eylül Üniversitesi İktisadi ve İdari Bilimler Fakültesi Dergisi, 28(2), 189-217. 


\section{M. ÖZÇALICI.}

ARAS, S., KOCAKOÇ, İ.D. (2016), "A New Model Selection Strategy in Time Series Forecasting with Artificial Neural Networks: IHTS", Neurocomputing, 174, 974-987.

ASADİ, S., HADAVANDİ, E., MEHMANPAZIR, F., NAKHOSTIN, M.M. (2012), "Hybridization of Evolutionary Levenberg-Marquardt Neural Networks and Data Pre-Processing for Stock Market Prediction", Knowledge-Based Systems, $35,254-258$.

ATAN, S.D., ÖZDEMIR, Z.A., ATAN, M. (2009), "Hisse Senedi Piyasasında Zayıf Formda Etkinlik: IMKB Üzerine Ampirik Bir Çalışma", Dokuz Eylül Üniversitesi İktisadi Ve İdari Bilimler Fakültesi Dergisi, 24(2), 33-48.

ATSALAKIS, G.S., PROTOPAPADAKIS, E.E., VALAVANIS, K.P. (2015), "Stock trend forecasting in turbulent market periods using neuro-fuzzy systems", Operational Research, DOI:10.1007/s12351-015-0197-6.

ATSALAKIS, G.S., VALAVANIS, K.P. (2009a), "Surveying Stock Market Forecasting Techniques - Part II: Soft Computing Methods", Expert Systems with Applications, 36(3), 5932-5941.

ATSALAKIS, G.S., VALAVANIS, K.P. (2009b), "Forecasting Stock Market Short-Term Trends Using A Neuro-Fuzzy Based Methodology", Expert Systems with Applications, 36, 10696-10707.

AVCI, E. (2009), "Stock Return Forecasts with Artificial Neural Network Models", Marmara Üniversitesi IIBBF Dergisi, 26(1), 443-461.

BAO, Y., XIONG, T., HU, Z. (2014). "Multi-step-ahead time series prediction using multiple-output support vector regression", Neurocomputing, 129, 482-493.

BOYACIOĞLU, M.A., KARA, Y. (2007), “Türk Bankac1lık Sektöründe Finansal Güç Derecelerinin Tahmininde Yapay Sinir Ağları Ve Çok Değişkenli İstatistiksel Analiz Tekniklerinin Performanslarının Karşılaştırılması", Dokuz Eylül Üniversitesi İktisadi ve İdari Bilimler Fakültesi Dergisi, 22(2), 197-217. 
CHANG, P.C., WANG, D., ZHOU, C. (2012), "A Novel Model by Evolving Partially Connected Neural Network for Stock Price Trend Forecasting", Expert Systems with Applications, 39, 611-620.

ÇALIŞKAN, M.M.T., DENİZ, D. (2015), "Yapay Sinir Ağlarıyla Hisse Senedi Fiyatları ve Yönlerinin Tahmini”, Eskişehir Osmangazi Üniversitesi İ̈BF Dergisi, 10(3), 177-194.

DİLER, A.İ. (2003), "IMKB Ulusal-100 Endeksinin Yönünün Yapay Sinir Ağları Hata Geriye Yayma Yöntemi İle Tahmin Edilmesi”, IMKB Dergisi, 7(25-26), 6581.

EDWARDS, R., VE MAGEE, J. (2007), Technical Analysis of Stock Trends, (9. Bask1), Taylor \& Francis Group, LLC, New York,.

FAMA, E.F (1965), "The Behavior of Stock-Market Prices", The Journal of Business, 38(1), 34-105.

HAGAN, M.T., DEMUTH, H.B., BEALE, M. (1996), Neural Network Design, PWS Publishing Company, USA.

HAYKIN, S. (1999), Neural Networks: A Comprehensive Foundation, Prentice Hall, India.

HORNIK, K., STINCHCOMBE, H.W. (1989), "Multilayer Feedforward Networks Are Universal Approximator", Neural Networks, 2(5), 359-366.

HUCK, N. (2010), "Pairs trading and outranking: The multi-step-ahead forecasting case". European Journal of Operational Research, 207, 1702-1716.

KARA, Y., BOYACIOĞLU, M.A., BAYKAN, Ö.K., (2011), "Predicting Direction of Stock Price Index Movement Using Artificial Neural Networks and Support 


\section{M. ÖZÇALICI.}

Vector Machines: The Sample of the Istanbul Stock Exchange", Expert Systems with Applications, 38, 5311-5319.

ÖZÇALICI, M. (2015), Hisse Senedi Fiyat Tahminlerinde Bilgi Işslemsel Zeka Yöntemleri: Uzman Bir Sistem Aracılığlyla BIST Uygulaması, Kahramanmaraş Sütçü İmam Üniversitesi, Sosyal Bilimler Enstitüsü, İşletme Ana Bilim Dalı, Doktora Tezi.

ÖZÇALICI, M. (2011), Özdüzenleyici Haritalar Yöntemiyle Banka Müşterilerinin Bölümlendirilmesi. Gaziantep Üniversitesi Sosyal Bilimler Enstitüsü, İşletme Ana Bilim Dalı, Yüksek Lisans Tezi.

PALIT, A.K., POPOVIC, D. (2005), Computational Intelligent in Time Series Forecasting: Theory and Engineering Applications, Springer. London.

TEKTAŞ, A., KARATAŞ, A. (2004), "Yapay Sinir Ağları Ve Finans Alanına Uygulanmas1: Hisse Senedi Fiyat Tahminlemesi", Atatürk Üniversitesi İktisadi ve İdari Bilimler Dergisi, 18(3-4), 337-349.

TORAMAN, C. (2008), "Demir-Çelik Sektöründe Yapay Sinir Ağları ile Hisse Senedi Fiyat Tahmini: Erdemir A.Ş. ve Kardemir A.Ş. Üzerine Bir Tahmin Uygulaması", Muhasebe ve Finansman Dergisi, 39, 44-57.

USLU, V.R., YOLCU, U., EĞRİOĞLU, E. ALADAĞ, Ç.H., BAŞARAN, M.A. (2012), "Yüksek Dereceli Bulanık Zaman Serisi Yaklaşımı ile Türkiye Enflasyon Öngörüsü”, Dokuz Eylül Üniversitesi İktisadi ve İdari Bilimler Fakültesi Dergisi, 27(1), 85-95.

YAKUT, E., ELMAS, B., YAVUZ, S. (2014), "Yapay Sinir Ağları ve Destek Vektör Makineleri Yöntemleriyle Borsa Endeksi Tahmini", Süleyman Demirel Üniversitesi İktisadi ve İdari Bilimler Fakültesi Dergisi, 19(1), 139-157.

XIONG, T., BAO, Y., HU, Z. (2013), "Beyond One-Step-Ahead Forecasting: Evaluation of Alternative Multi-Step-Ahead Forecasting Models For Crude Oil Prices", Energy Economics, 40, 405-415. 
Dokuz Eylül Üniversitesi İktisadi ve İdari Bilimler Fakültesi Dergisi Cilt:31, Sayl:2, Yll:2016, ss. 209-227

Ek-1. Her Bir Hisse Senedi İçin Girdi Değişkenleri Arasındaki Pearson Korelasyon

Katsayis1

\begin{tabular}{|l|l|l|l|}
\hline & \multicolumn{3}{|l|}{ Değişkenler Arasi Korelasyon Katsay1s1 } \\
\hline Hisse Senedi & \%D - SMA(10) & \%D - MACD & MACD - SMA(10) \\
\hline AKBNK & 0,237 & 0,4315 & $-0,0003$ \\
\hline ARCLK & 0,0908 & 0,4427 & $-0,0649$ \\
\hline BIMAS & 0,1694 & 0,2716 & 0,035 \\
\hline CCOLA & $-0,0017$ & 0,3917 & $-0,0382$ \\
\hline DOAS & 0,1852 & 0,4116 & 0,0507 \\
\hline EKGYO & 0,5307 & 0,2714 & 0,0005 \\
\hline ENKAI & 0,2089 & 0,4584 & 0,0061 \\
\hline EREGL & 0,0991 & 0,4733 & 0,01 \\
\hline FROTO & 0,0896 & 0,3842 & $-0,0786$ \\
\hline GARAN & 0,2415 & 0,4531 & 0,0014 \\
\hline HALKB & 0,3642 & 0,3787 & 0,0284 \\
\hline ISCTR & 0,2077 & 0,483 & 0,0195 \\
\hline KCHOL & 0,0988 & 0,4644 & $-0,0458$ \\
\hline KOZAL & 0,1738 & 0,4256 & 0,007 \\
\hline KRDMD & 0,072 & 0,467 & $-0,1102$ \\
\hline OTKAR & 0,1036 & 0,3871 & $-0,1493$ \\
\hline PETKM & 0,2466 & 0,4636 & 0,0508 \\
\hline PGSUS & 0,0879 & 0,1522 & $-0,0008$ \\
\hline SAHOL & 0,1443 & 0,4562 & $-0,0282$ \\
\hline SISE & 0,1621 & 0,446 & $-0,052$ \\
\hline TAVHL & 0,1911 & 0,3848 & $-0,0747$ \\
\hline TCELL & 0,1564 & 0,424 & 0,0049 \\
\hline THYAO & 0,1343 & 0,4837 & $-0,0091$ \\
\hline TKFEN & 0,2756 & 0,4484 & 0,0192 \\
\hline TOASO & 0,1568 & 0,4271 & $-0,0143$ \\
\hline TTKOM & 0,2881 & 0,4504 & 0,0255 \\
\hline TUPRS & 0,2023 & 0,4533 & $-0,0142$ \\
\hline ULKER & 0,0723 & 0,3883 & $-0,0593$ \\
\hline VAKBN & 0,2123 & 0,4771 & 0,019 \\
\hline YKBNK & 0,2326 & 0,4659 & 0,0339 \\
\hline & & & \\
\hline & & & \\
\hline & & & \\
\hline
\end{tabular}

